\title{
LOCALISATION OF WASTE THERMAL TREATMENT PLANT WITH MULTI-CRITERIA ANALYSYS
}

\author{
Elżbieta Szafranko' \\ 1 University of Warmia and Mazury in Olsztyn, The Faculty of Geodesy, Geospatial and Civil Engineering, \\ 10-724 Olsztyn, Heweliusza Str. 4, Poland, e-mail: elasz@uwm.edu.pl
}

Received: 2017.03.04

Accepted: 2017.04.05

Published: 2017.05.02

\begin{abstract}
At the stage of planning a construction project, an assessment must be made of possible variants of its implementation. Variants may pertain to the localisation, economic aspects as well as the actual construction and design solutions. This article deals with the question of selecting the localisation for a construction project consisting of building a plant for thermal treatment of waste. In order to chose an optimal location, first we must establish assessment criteria which will guide us through a supported choice procedure, and next we should apply a method for the evaluation of variant solutions. Some criteria refer to measurable phenomena and are therefore easy to be defined and weighed. Others require descriptions, designating the right scale and proper methods for their identification. The article contains an example of a set of criteria and a case study of using multi-criteria analytical methods for selecting the location to develop a specific construction project such as a Waste Thermal Treatment Plant. Some well-known methods are compared with the approach proposed by the author. The methods applied in analyses have certain advantages and disadvantages. Irrespective of which method is applied, a reliable and trustworthy analysis of the location for a future construction project brings about many benefits. Such an analysis creates an opportunity to become aware of problems and obstacles which one may come across both while executing the project and in the many years to come, when the raised construction is used.
\end{abstract}

Keywords: multicriteria methods, optimal localization, variants of construction project, waste thermal treatment plant

\section{AIMS AND BACKGROUND}

Numerous decisions must be made when executing a construction project. Most are taken prior to making a design or commencing work on a building site. Success of the whole undertaking depends on the proper performance of all subsequent stages. Amongst the most important decisions is the one about the location of a building. It is often taken into consideration when evaluating variants of a building project. It should be mentioned that the choice of a location is not a starightforward one and the selection is limited by a number of conditions, which enable us to define assessment criteria for the problem submitted to our examination [Rousis 2008, Cinelli et all 2014].
When solving a multi-criteria problem, we often strive to express our expectations with the help of just one criterion, which aggregates all significant consequences of the problem. Thus, we deal with a single-criterion analysis, in which every potential variant is assessed relative to just one criterion, selected a priori, for example costs, outputs, time needed to execute the project, profit, profitability, benefits. A single criterion, however, is not recommended in a case of complicated investment processes. It is neither fully reliable nor does it possess such properties that would allow us to demonstrate and analyse a whole spectrum of quetsions and problems associated with planning, designing and building constructions. Multi-criteria decision making, in contrast to an 
analysis based on a single criterion, facilitates the creation of a coherent family of criteria, which will function as an instrument for full and complete communication, and this should enable us to formulate, justify and transform preferences during a decision-making process. Thus, when planning a construction project which may intefere with the protection and conservation of nature and for which it is necessary to solve many problems, multi-criteria methods for supporting decisions are highly recommended [Tatham and all 2014].

\section{METHODOLOGY}

Some of the methods for multi-criteria analysis are mathematically more complex and some are simpler. Civil engineers must evaluate variants of construction projects all the time, which is why simpler methods, like a scoring technique, a checklist or a comparison of costs and benefits, are used in everyday practice. These methods do not require the user to possess high mathematical skills, but the results do not take into account all aspects and conditions underlying a given decision [Keršulienè and Turskis 2014].

Literature provides us with information about numerous, more advanced calculation methods [Szafranko 2014]. When making a choice of a method, one should consider such aspects as: the way in which input data are prepared and verified, the applied mathematical apparatus, the ease of using a method and verifying the results, readibility and clarity of the results. Another issue worth considering is the subjectivity of an assessment because a number of widely used methods are based on subjective opinions of people who are involved in a given project. Consequently, partial assessments as well as the final result can be burdened with some error, which must not be overlooked. Subjectivity can also be assigned to methods in which qualitative conditions are considered. An assessment achieved on the basis of a criterion can be obvious provided it is the so-called measurable factor [Karagiannidis and Perkoulidis 2009]. When qualitative factors are evaluated, an objective assessment can be achieved if one of the following two approaches is adopted. The first one is to produce a descriptive assessment while the other one requires that a numerical measuring scale be implemented [Haider and Tesfamariam 2015]. Non-measurable factors are frequently en- countered when planning a construction project. They can be included in our analysis if it is performed according to such multi-crietria methdos as the MCE Analysis, AHP or Indicator Method [Rong-Hui and all 2014, Gadakh 2014, Szafranko 2015]. However, it is difficult to estimate the range of error that the final results will be loaded with. It can be presumed that these are acceptable approximations, which require adidtional interpretation prior to making a rational decision.

Well-known method includng a scoring assessment will be compared with the approach proposed by the author with the Indicator Method.

\section{INDICATOR METHOD}

The starting point for a multi-criteria analysis conducted with the Indicator Method (same as with other methods of multi-criteria analyses) is to identify the criteria which we will use for an assessment of individual variants of an investment project [Szafranko 2015]. The degree to which each of the variants meets the predefined criteria is the most important stage of our analysis. Because the Indicator Method allows us to include negative effects of a planned building project, they should be considered as well. A questionnaire addressed to experts differs from other types of surveys mainly in that it lets respondents evaluate negative effects of the analysed project [Szafranko 2015]. Thus, a survey comprises a question about the effects measured on a different scale. When making an assessment of the envisaged construction project according to this method, the criteria included in the process can be evaluated on a scale, for example, from -5 to +5 . This approach allows us to assess both positive and negative effects of the analysed project, which is particularly important and pertinent when evaluating the impact on the natural and social environment [Szafranko 2015].

The number in the top left-hand corner of each cell describes a direct effect of the development project while the one in the bottom righthand corner refers to its indirect effect. In the middle, you will see the sum of the effects multiplied by the weight. The sum of individual effects is a partial assessment (Table 1).

The partial assessment on the effect of the $j^{\text {th }}$ variant on the $\mathrm{i}^{\text {th }}$ criterion:

$$
Q i j=\left(P_{i j}+R_{i j}\right) * W_{i}(1)
$$


Table 1. An example of matrix for calculations by the indicator method

\begin{tabular}{|c|c|c|c|c|c|c|c|c|c|c|c|}
\hline No & Criterion & \multicolumn{2}{|c|}{ Variant 1 of the investment } & \multicolumn{2}{|c|}{ Variant 2 of the investment } & \multicolumn{2}{c|}{ Variant 3 of the investment } & $\begin{array}{c}\text { Weight of the } \\
\text { criterion }\end{array}$ \\
\hline 1 & $\mathrm{~A} 1$ & $\mathrm{P}_{11}$ & $\mathrm{Q}_{11}$ & $\mathrm{R}_{11}$ & $\mathrm{P}_{12}$ & $\mathrm{Q}_{12}$ & $\mathrm{R}_{12}$ & $\mathrm{P}_{13}$ & $\mathrm{Q}_{13}$ & $\mathrm{R}_{13}$ & $\mathrm{~W}_{1}$ \\
\hline 2 & $\mathrm{~A} 2$ & $\mathrm{P}_{21}$ & $\mathrm{Q}_{21}$ & $\mathrm{R}_{21}$ & $\mathrm{P}_{22}$ & $\mathrm{Q}_{22}$ & $\mathrm{R}_{22}$ & $\mathrm{P}_{23}$ & $\mathrm{Q}_{23}$ & $\mathrm{R}_{23}$ & $\mathrm{~W}_{2}$ \\
\hline
\end{tabular}

where: $P_{i j}$ - direct effect of a subsequent variant in the context of criterion $\mathrm{A}$;

$R_{i j}$ - indirect effect of a subsequent variant in the context of criterion A; $W_{i}-$ weight of criterion A

\section{EXPERIMENTAL}

\section{A brief description of the project}

Execution of projects which involve construction of facilities for thermal waste processing is a complicated task. Such facilities comprise installations for waste incineration, an installation for slag valorisation, an installation for the solidification and chemical stabilisation of ash and other residues from fume filters, a depot for unloading the waste, waste collection and sorting, as well as some office and staff rooms. The plant must satisfy certain requirements, e.g. total capacity and the capacity of an incineration line, a pre-defined working time, etc. In line with the previously determined elements of the whole plant, basic conditions that a chosen localisation must fulfil have been identified in our case study. For instance, the chosen site should not border with compact housing developments and must cover at least 4.0 ha. The land relief should be suitable for an easy distribution of the required infrastucture according to the design of all technological lines. The geographical characteristics of each location as well as the morphological structure of land lots available for our development were analysed alongside the local climate, including average annual temperature, annual sum of precipitation and a wind rose for each site. Special attention was paid to surface water and groundwater as well as the water management and nature protection issues.

\section{Determination of the criteria for the selection of localisation}

Having analysed all the requirements that the future plant would have to satisfy, all the information relevant for making a decision about the location of the plant was divided into several groups of criteria:

1. Technical and legal aspects;

2. Land properties;

3. Ecology;

4. Access and Logistics;

5. Economic issues.

Furthermore, certain subcriteria were identified in each group. Such subcriteria often prevail in the making of final decisions:

1. Technical and legal aspects

1.1. The current use of the land, the legal status of the land lot,

1.2. The compliance with the spatial management plan,

1.3. Technical infrastructure on the land lot,

1.4. Distance to the nearest heat distribution station and electric power transformation station,

1.5. Direct access to the land lot, access roads,

1.6. Space available for temporary storage of waste generated at the plant,

2. Land properties

2.1. Options to locate all necessary construction and technical infrastructure on the land lot,

2.2. Size of the land lot,

2.3. Distance to water courses (risk of flooding),

3. Ecology

3.1. Presence of areas of protected nature or protected species,

3.2. Presence of areas protected as archeological or heritage sites,

3.3. An opportunity to reduce emission of pollutants from a conventional municipal heat and power plant by supplying the town with extra energy.

4. Transport and logistics

4.1. Transportation solutions,

4.2. Distance over which waste from communes must be transported,

4.3. Possibility to transport some of the waste by rail.

5. Social aspects

5.1. Distance to housing estates, 
5.2. Potential social acceptance,

5.3. Risk of social conflict.

6. Economic issues

6.1. The need to consider outlays for building the missing technical and communal infrastructure,

6.2. The need to cover costs to couple the heat and power system with a new source of energy,

6.3. Purchasing costs to buy a land lot.

\section{Description of available locations}

Five possible locations were identified.

\section{Location L1}

A Local Zoning Plan (LZP) is being developed but the construction project does not comply with the LZP.The area of the site is 11 ha. Access to infrastructure provided. Lack of a possibility to store waste products and ashes; a possibility of building a storage facility. A river flows 600 $\mathrm{m}$ west of the land parcel. $200 \mathrm{~m}$ north of the site there is a water canal. No direct risk of flooding. Near the site there are 9 nature parks, 72 natural monuments and 2 ecological sites. There are no objects protected as archeological or heritage sites. There is a potential energy recipient. Access to a road and railroad available. $100 \mathrm{~m}$ to the south of the lot there is some housing development. The land lot borders with garden allotments - a high risk of social conflict. It is necessary to expand the transmission network. The site is a property of the town and commune - no costs of purchase.

\section{Location L2}

Has a local zoning plan, the project complies with the LZP. Covers 10 ha. Access to infrastructure available. No possibility to store waste products and ashes, but a storage facility can be built. Rivers: $400 \mathrm{~m}$ to the north, $500 \mathrm{~m}$ to the south and $1,500 \mathrm{~m}$ to the east. A water body $1000 \mathrm{~m}$ to the south-east. No direct risk of flooding. $400 \mathrm{~m}$ away from the site there are habitats of numerous bird species. The land parcel borders with a set of buildings and structures under the protection of the Heritage Conservation Office. There is a potential client for heat energy. Direct access to a state road available but difficult due to a low railway bridge over the access road. It will also be necessary to designate some of the land to building a railroad. A residential estate with detached houses $400 \mathrm{~m}$ of the northern border to the land parcel. Moderate risk of social conflict - low degree of social approval. Necessary to modernise the road infrastructure. Necessary to build the infrastructure for heat transmission. Property of the State Treasury and the Town Council - no costs of purchase the land site.

\section{Location L3:}

No LZP. The Zoning study designates the site as suitable for production and services. The whole site covers 200 ha of fallow land. Access to infrastructure ensured. No possibility to store waste products and ashes, a possibilty of building a storage facility. There is a river flowing through the lot; to the south, there is a canal adjacent to the lot's border and the Lagoon lies to the north. Some of the river bed and the canal are not regulated. A risk of flooding. No objects nearby protected as nature, archeological or historical monuments. There is a potential client for energy. Access through a town street connecting to a Provincial Road. Near the site there is a road junction and railway infrastructure. Housing development composed of detached houses some $300 \mathrm{~m}$ away. A moderate risk of social conflict - low social approval. Necessary to build water pipes, sewarages and power transmission lines. Necessary to build infrastructure for heat transmission. Property of the State Treasury but the land parcel controlled by the Power Plant - costs of purchase expected.

\section{Location L4}

According to the provisions of the 1ZP, the land lot can be developed under a heat and power plant, pump station, also generating energy from waste. The area is 22.5 ha. Access to infrastructure available. A possibility for short-term storage of waste products. North of the land lot there is a stream which carries away rainwater and municipal wastewater. No direct threat of flooding. Nearby there are no objects or sites protected as natural or man-made monuments. There is a potential client for the energy produced. Access to the land lot directly from a public street - the street grid suitable for wheeled transport. Two road junctions planned to be built. No railway connection. The nearest multi-flat houses about $800 \mathrm{~m}$ away - a low risk of social conflict. Necessary to build a new transformer station and about $2000 \mathrm{~m}$ of electric supply cable. Property of the town - no costs of purchase. 


\section{Location L5}

According to the LZP, the land is to be developed under a heat generating plant, a pump station or other heat generation facilities. It covers 15 ha. Access to infrastructure available. Temporary storage of waste products possible. An industrial waste disposal site near the land lot. Rivers: about $2 \mathrm{~km}$ to thee south and $1,200 \mathrm{~m}$ to the north of the lot's boundary. The land lot is not exposed to a direct risk of flooding. A landscape park about $1 \mathrm{~km}$ to the south of the lot. No objects protected as archeological or heritage sites. Distance from the lot to the motorway - about $4 \mathrm{~km}$. There is a potential client for energy. Near the lot, there is a housing estate and a hospital - social conflict highly possible. Social approval of the development - on a low level. Necessary to re-construct the local road infrastructure. Property - the State Treasury - costs of purchase expected.

\section{SOLVING THE PROBLEM WITH MULTI- CRITERIA ANALYSIS METHODS}

In order to choose one of the five locations described above, a number of data must be considered. It is not easy to make a straightfoward choice in such a complicated situation. Therefore, it is suggested to apply various analytical methods, including multi-criteria analyses. Below, one of the most popular traditional approaches are discussed, includng a scoring assessment of available locations. The Assessment Method consisting in assigning scores is one of the simples and therefore most popular solutions in an engineer's practice. Scores are assigned to the analysed variants for satisfying the requirements. Our assessment was made according to the previously established criteria, which were scored on a scale from 0 to 3 points. The scores represented degrees of satisfying criteria: 0 - unsatisfactory, 1 - satisfactory, 2 - good, 3 - very good. The calculations are shown in Table 2.

This method ensures a rather direct assessment and accounts for all subcriteria defined within groups of main criteria. As seen from the above results, location 4 scored the highest (56 points). The second place is occupied by two locations, 2 and 5, while location 1 was the third best option. The worst alternative was location 3 . The best location scored 16 highest marks, 4 good marks and 1 unsatisfactory mark.
The Indicator Method is an interesting verison of a multi-criteria method because it represents a slightly different approach to the assessment of variants. A matrix of comparisons contains local and global effects of the project while possible negative effects are presented in the form of negative scores. In our case, when 5 location variants had to be analysed, the analysis included the same criteria, that is technical and legal as well as social ones.

A scale from -5 to +5 was applied. The calculations based on a comparison matrix for group 1 criteria are comprised in Table 3, while Table 4 shows results of comparisons for group 5 criteria.

The analysis performed according to the Indicator Method suggested that location 4 was the best option, same as in the earlier analyses (Table 5). The worst choice, that is the one which satisfied most poorly the requirements set for the planned construction project, proved to be variant 3. This ranking list of the analysed variants was most strongly justified by an assessment of the technical and legal conditions.

The reason is probably a higher number of subcriteria, which together potentially generated much more points. In addition, the low position of variant 5 obviously resulted from the negative scores which appeared in its assessment, implicating that the project pursued in that location would have adverse social effects.

\section{RESULTS AND DISCUSSION}

The article presents an analysis performed with three different methods, all of which based on the same assumptions. They all assess to what extent each variant satisfies predefined criteria and the assessment process engages experts. In each method, an assessment is expressed as a score and although different scales are applied, the results enable the user to identify a certain hierarchy of the analysed locations.

The first method is the simplest one. It shows final scores assiged to the variants which take into account scores given to subcriteria and sums of scores for each category assessed. The structure of the assessment is illustrated in Figure 1.

For a reliable comparison of the results of an analysis, the score method should be applied to criteria 1 and 5 exclusively. These results are plotted in diagram on Figure 2. 
Table 2. Score assessment of the potential locations

\begin{tabular}{|c|c|c|c|c|c|c|}
\hline \multirow{2}{*}{ Criterion } & \multirow{2}{*}{ Subcriterion } & \multicolumn{5}{|c|}{ Localisation } \\
\hline & & L1 & L2 & L3 & L4 & L5 \\
\hline \multirow{7}{*}{$\begin{array}{l}\text { Technical and } \\
\text { legal aspects }\end{array}$} & 1.1. The current use of the land, the legal status of the land lot & 2 & 2 & 1 & 3 & 1 \\
\hline & 1.2. The compliance with the spatial management plan & 0 & 3 & 1 & 3 & 1 \\
\hline & 1.3. Technical infrastructure on the land lot & 2 & 2 & 1 & 3 & 3 \\
\hline & $\begin{array}{l}\text { 1.4. Distance to the nearest heat distribution station and electric } \\
\text { power transformation station }\end{array}$ & 3 & 2 & 1 & 3 & 3 \\
\hline & 1.5. Direct access to the land lot, access roads & 3 & 2 & 2 & 2 & 1 \\
\hline & $\begin{array}{l}\text { 1.6. Space available for temporary storage of waste generated at } \\
\text { the plant }\end{array}$ & 1 & 2 & 2 & 2 & 2 \\
\hline & SUM: & 11 & 13 & 8 & 19 & 11 \\
\hline \multirow{4}{*}{ Land properties } & $\begin{array}{l}\text { 2.1. Options to locate all necessary construction and technical } \\
\text { infrastructure on the land lot }\end{array}$ & 3 & 1 & 2 & 3 & 3 \\
\hline & 2.2. Size of the land lot & 3 & 3 & 3 & 3 & 3 \\
\hline & 2.3. Distance to water courses (risk of flooding), & 2 & 2 & 0 & 3 & 2 \\
\hline & SUM: & 8 & 6 & 5 & 9 & 8 \\
\hline \multirow{4}{*}{ Ecology } & 3.1. Presence of areas of protected nature or protected species, & 2 & 2 & 2 & 3 & 3 \\
\hline & 3.2. Presence of areas protected as archeological or heritage sites & 3 & 2 & 3 & 3 & 3 \\
\hline & $\begin{array}{l}\text { 3.3. An opportunity to reduce emission of pollutants from a } \\
\text { conventional municipal heat and power plant by supplying the } \\
\text { town with extra energy }\end{array}$ & 2 & 3 & 2 & 3 & 3 \\
\hline & SUM: & 7 & 7 & 7 & 9 & 9 \\
\hline \multirow{4}{*}{$\begin{array}{l}\text { Transport and } \\
\text { logistics }\end{array}$} & 4.1. Transportation solutions & 3 & 1 & 2 & 2 & 1 \\
\hline & $\begin{array}{l}\text { 4.2. Distance over which waste from communes must be } \\
\text { transported, }\end{array}$ & 2 & 2 & 1 & 3 & 2 \\
\hline & 4.3. Possibility to transport some of the waste by rail & 2 & 2 & 2 & 0 & 3 \\
\hline & SUM: & 7 & 5 & 5 & 5 & 6 \\
\hline \multirow{4}{*}{ Social aspects } & 5.1. Distance to housing estates & 1 & 3 & 2 & 3 & 1 \\
\hline & 5.2. Potential social acceptance & 1 & 1 & 2 & 3 & 1 \\
\hline & 5.3. Risk of social conflict & 1 & 2 & 2 & 3 & 1 \\
\hline & SUM: & 3 & 6 & 6 & 9 & 3 \\
\hline \multirow{4}{*}{ Economical } & $\begin{array}{l}\text { 6.1 The need to consider outlays for building the missing technical } \\
\text { and communal infrastructure }\end{array}$ & 1 & 2 & 1 & 2 & 2 \\
\hline & $\begin{array}{l}\text { 6.2. The need to cover costs to couple the heat and power system } \\
\text { with a new source of energy }\end{array}$ & 2 & 2 & 2 & 3 & 3 \\
\hline & 6.3. Purchasing costs to buy a land lot & 3 & 2 & 1 & 3 & 1 \\
\hline & SUM: & 6 & 6 & 4 & 8 & 6 \\
\hline \multicolumn{2}{|r|}{ Total score points: } & $\underline{42}$ & $\underline{43}$ & $\underline{35}$ & $\underline{56}$ & $\underline{43}$ \\
\hline
\end{tabular}

Table 3. The calculations based on a comparison matrix for group 1 criteria

\begin{tabular}{|c|c|c|c|c|c|c|c|c|c|c|c|c|c|c|c|c|}
\hline No & \multicolumn{3}{|c|}{ Variant 1 } & \multicolumn{3}{|c|}{ Variant 2 } & \multicolumn{3}{c|}{ Variant 3 } & \multicolumn{3}{c|}{ Variant 4 } & \multicolumn{3}{c|}{ Variant 5 } & Weight \\
\hline 1.1 & 3 & 10.5 & 4 & 2 & 9 & 4 & 1 & 4.5 & 2 & 5 & 12 & 3 & 2 & 4.5 & 1 & 0.15 \\
\hline 1.2 & 0 & 3 & 1 & 4 & 27 & 5 & 2 & 9 & 1 & 4 & 27 & 5 & 1 & 6 & 1 & 0.3 \\
\hline 1.3 & 4 & 14 & 3 & 3 & 14 & 4 & 1 & 2 & 0 & 5 & 20 & 5 & 4 & 16 & 4 & 0.2 \\
\hline 1.4 & 4 & 9 & 5 & 3 & 5 & 2 & 1 & 3 & 2 & 4 & 7 & 3 & 5 & 8 & 3 & 0.1 \\
\hline 1.5 & 5 & 20 & 5 & 2 & 6 & 1 & 1 & 4 & 1 & 3 & 14 & 4 & 2 & 6 & 1 & 0.2 \\
\hline 1.6 & 1 & 1 & 1 & 1 & 1.5 & 2 & 2 & 2 & 2 & 3 & 2.5 & 2 & 2 & 2 & 2 & 0.05 \\
\hline Sum & & 57.5 & & & 62.5 & & & 24.5 & & & 82.5 & & & 42.5 & & 1.0 \\
\hline
\end{tabular}

Table 4. The calculations based on a comparison matrix for group 5 criteria

\begin{tabular}{|c|c|c|c|c|c|c|c|c|c|c|c|c|c|c|c|c|c|}
\hline No & \multicolumn{3}{|c|}{ Variant 1 } & \multicolumn{3}{c|}{ Variant 2 } & \multicolumn{3}{c|}{ Variant 3 } & \multicolumn{3}{c|}{ Variant 4 } & \multicolumn{3}{c|}{ Variant 5 } & Weight \\
\hline 5.1 & -1 & 0.5 & 2 & 3 & 2.5 & 2 & 2 & 2.5 & 3 & 4 & 4.5 & 5 & -1 & 0 & 1 & 0.5 \\
\hline 5.2 & -2 & -1.5 & -3 & 2 & 1.5 & 3 & 2 & 1.2 & 2 & 3 & 1.5 & 2 & 1 & -0.3 & -2 & 0.3 \\
\hline 5.3 & -1 & -0.6 & -2 & 2 & 0.8 & 2 & 2 & 0.8 & 2 & 2 & 0.8 & 2 & -1 & -0.8 & -3 & 0.2 \\
\hline Sum & & -1.6 & & & 4.8 & & & 4.5 & & & 6.8 & & & -1.1 & & 1.0 \\
\hline
\end{tabular}


Table 5. Evaluation of analyzd variants by the Indicator Method

\begin{tabular}{|c|c|c|c|c|c|}
\hline No & Variant 1 & Variant 2 & Variant 3 & Variant 4 & Variant 5 \\
\hline Cr1 & 57.5 & 62.5 & 24.5 & 82.5 & 42.5 \\
\hline Cr5 & -1.6 & 4.8 & 4.5 & 6.8 & -1.1 \\
\hline Sum & 55.9 & 67.3 & 29.0 & 89.3 & 41.4 \\
\hline
\end{tabular}

The second method discussed in this paper is an Indicator Method modified by the author. It allows the user to take into account the specific character of each development project as well as the negative assessement versus some of the criteria, as seen in diagrams (Fig. 3, 4) This method is slightly different in character and it is difficult to compare it step by step with the methods presented earlier. However, the final result coincides with the solutions achieved with the other two methods. Noteworthy is the option of including the impact of negative effects caused by the implementation of the analysed construction project, although the incorporation of negative values leads to larger discrepancies in values generated by the performed analysis. Thus, it is suggested to apply the Indicator Method separately for an assessment of criteria where negative effects can be expected and separately to the criteria described with positive scores only. This method allows the user to elaborate a graphically interesting interpretation of the results.

The diagrams illustrating the cummulative effect of an analysis of the distribution of values (Fig. 3, 4, 5, 6) show a participation trend for each value in time. The middle value in these diagrams is intensified by its multiplication by a weight assiged to each of the criteria.

\section{CONCLUSIONS}

In a complex and multi-faceted project such as a plan to raise a building structure, the choice of a suitable location is the problem whose weight cannot be overestimated. This issue gains importance when a development project itself gives very little freedom as regards to its location due to technical and techological constraints as well as a possible burden on the environment. In our case study, five locations were submitted to analyses. Six groups of criteria for an assessment of the locations were chosen. The results achieved with two methods are convergent and the ranking list of the solutions arising from our analyses can be seen in Table 6 .

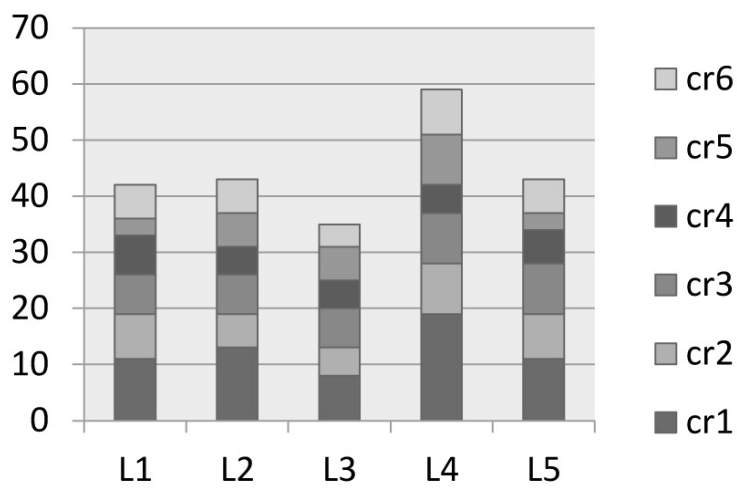

Figure 1. Complete assesment of variants with

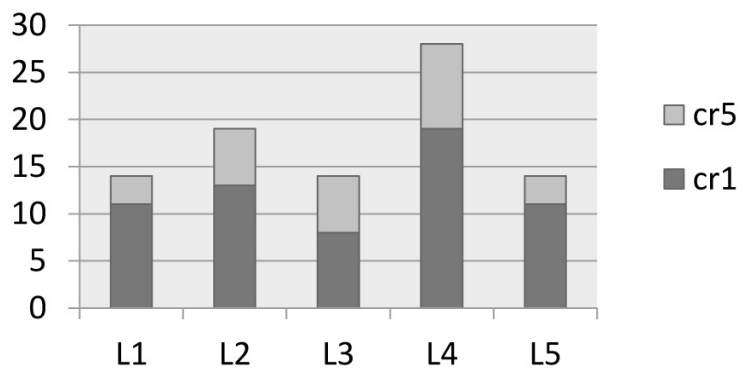

Figure 2. Assessment including only criteria 1 and 5 the score method
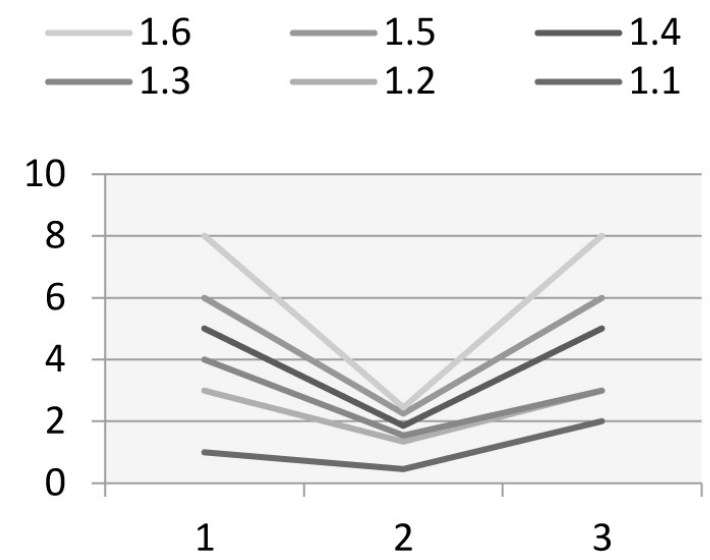

Figure 3. Variant 3 (lowest score cr1)

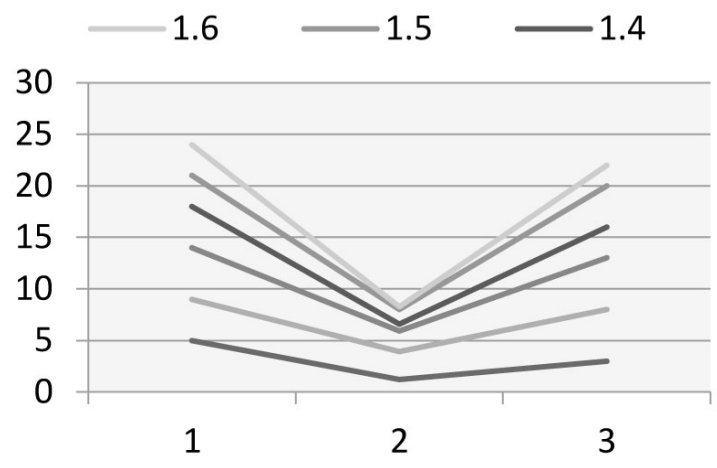

Figure 4. Variant 4 (highest score cr1) 


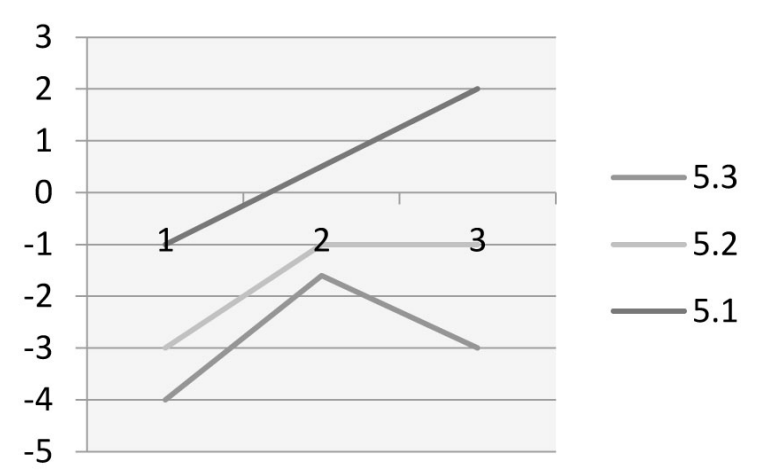

Figure 5. Variant 1 (lowest score cr5)

Table 6. Summary table

\begin{tabular}{|l|c|c|c|c|c|}
\hline \multicolumn{1}{|c|}{ Method/Variant } & L1 & L2 & L3 & L4 & L5 \\
\hline Assessment Method & 4 & 2 & 5 & 1 & 2 \\
\hline Indicator Method & 3 & 2 & 5 & 1 & 4 \\
\hline
\end{tabular}

As demonstrated, the results are convergent and suggest that same best solutions. The methods applied in our analyses have certain advantages and disadvantages. The first one, the score method, is a simple method for an impromptu application. It enables the user to make a rapid assessment without additional analyses. The Indicator Method, proposed by the author, despite its complexity and complicated calculations it necessitates, allows the user to evaluate any number of variants and to take into consideration different criteria. Another advantage of the method is that evaluation matrices can contain negative values which correspond to negative effects of the planned project.

Irrespective of which method is applied, a reliable and trustworthy analysis of the location for a future construction project brings about many benefits. Such an analysis creates an opportunity to become aware of problems and obstacles which one may come across both while executing the project and in the many years to come, when the raised construction is used.

\section{REFERENCES}

1. Karagiannidis A., Perkoulidis G. 2009. A multicriteria ranking of different technologies for the anaerobic digestion for energy recovery of the

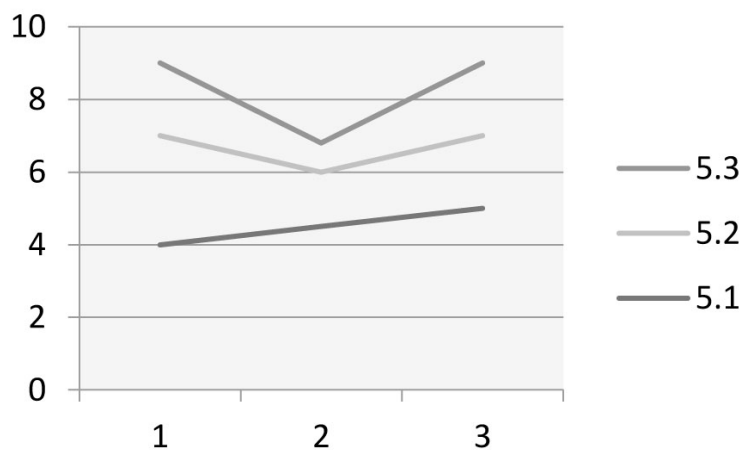

Figure 6. Variant 4 (highest score cr5)

organic fraction of municipal solid wastes. Bioresource technology 100(8), 2355-2360.

2. Rousis K., et al. 2008. Multi-criteria analysis for the determination of the best WEEE management scenario in Cyprus. Waste Management (28), 1941-1954.

3. Cinelli M. S. R., et all:. 2014. Analysis of the potentials of multi criteria decision analysis methods to conduct sustainability assessment.Ecological Indicators (46), 138-148.

4. Haider S. R. H., Tesfamariam S. 2015. Selecting performance indicators for small and medium sized water utilities: Multi-criteria analysis using ELECTRE method. Urban Water Journal 12(4), 305-327.

5. Rong-Hui C., Yuanhsu L., Ming-Lang T. 2014. Multicriteria analysis of sustainable development indicators in the construction minerals industry in China. Resources Policy 50(C), 134-141.

6. Tatham K. E., Daniel Eisenberg A., Linkov I. 2014. Sustainable urban systems: a review of how sustainability indicators inform decisions. Sustainable Cities and Military Installations. Springer Netherlands,

7. Szafranko E. 2015. Applicability of the indicator method to evaluation of road building projects. News in Engineering (1), pp. 1-7.

8. Szafranko E. 2014. Ways to determine criteria in multi-criteria methods applied to assessment of variants of a planned building investment. Technical Transaction 2B(6), 49-56.

9. Keršulienė V., Turskis Z. 2014. An integrated multi-criteria group decision making process: selection of the chief accountant. Procedia-Social and Behavioral Sciences (110), 897-904.

10. Gadakh V. S. 2014. Application of complex proportional assessment method for vendor selection. International Journal of Logistics Research and Applications 17(1), 23-34. 